the development of an allergy to rodents.

With Rusch as one of the co-editors, several of his former collaborators and others have contributed a series of essays describing the progress achieved in the study of Physarum. The collection will be of value to all who work with the organism and to others who wish to learn about its peculiarities for the first time.

The potential of genetic studies is emphasized in several of the articles, and the defined strains now available make possible, for example, the biochemical analysis of mutants defective in their ability to undergo the amoebal--plasmodial transition. Heat-sensitive mutants have been isolated in several laboratories and there is optimism that this class will contribute to our understanding of the control of the synchronous nuclear division cycle in the plasmodial phase. Here, the major challenge, as Holt points out in the first article, is to relate the coordinated replication of the genome to the control of nuclear division.

It is a tribute to the interest that Rusch was able to stimulate that most areas of research on Physarum can be covered by his former associates. Transcription, the nuclear replication cycle, genetics and details of the different developmental phases are amongst the topics described.
Throughout there is a discussion of possible areas of progress, although some of the suggestions have a slightly frenetic ring, more appropriate to a grant application than to a collection of critical essays. Another minor criticism is the overlap in details provided in the different chapters. This could have been avoided by stringent editorial control; on the other hand, the argument for repetition is that it does enable each essay to be read individually, and the book as a whole can certainly be recommended.

G. Turnock is a Senior Lecturer in Biochemistry at the University of Leicester.

\title{
All you wanted to know about inflammation
}

\section{J. L. Gordon}

The Cell Biology of Inflammation. Handbook of Inflammation, Vol. 2. Edited by Gerald Weissman. Pp.714. (Elsevier/North-Holland Biomedical: 1980.) Dfl. 230, $\$ 112.25$.

THE topics embraced by the title Cell Biology of Inflammation cover a fair proportion of many lecture courses in preclinical pathology and also touch on several aspects of fundamental research into cell biology - including cell maturation, adhesion, locomotion, phagocytosis, secretion and intercellular interactions - as well as tissue catabolism, remodelling and repair. Any editor attempting to assemble a book under this catch-all title is faced with a daunting task.

The first point to make, therefore, is that this book succeeds unusually well - better than any other single volume I have read. Several of the authors are acknowledged leaders in their field, and the overall quality is high, with some of the chapters being quite outstanding. I particularly liked Dee Bainton's general view of "The Cells of Inflammation', and there are two excellent contributions on mononuclear

\section{Until winning isn't everything, the public is damned.}

Nuclear waste v. cheap energy; the DC-10 disaster v. air travel; genetic engineering v. reducing birth defects. Complex socioscientific issues like these cannot be adequately addressed by our "either/or" system of dispute resolution, asserts legal scholar Milton R. Wessel. How to truly serve the public interest-by replacing winner-take-all adversary law with "the rule of reason"-is spelled out in SCIENCE AND CONSCIENCE, a work that every concerned citizen should read.

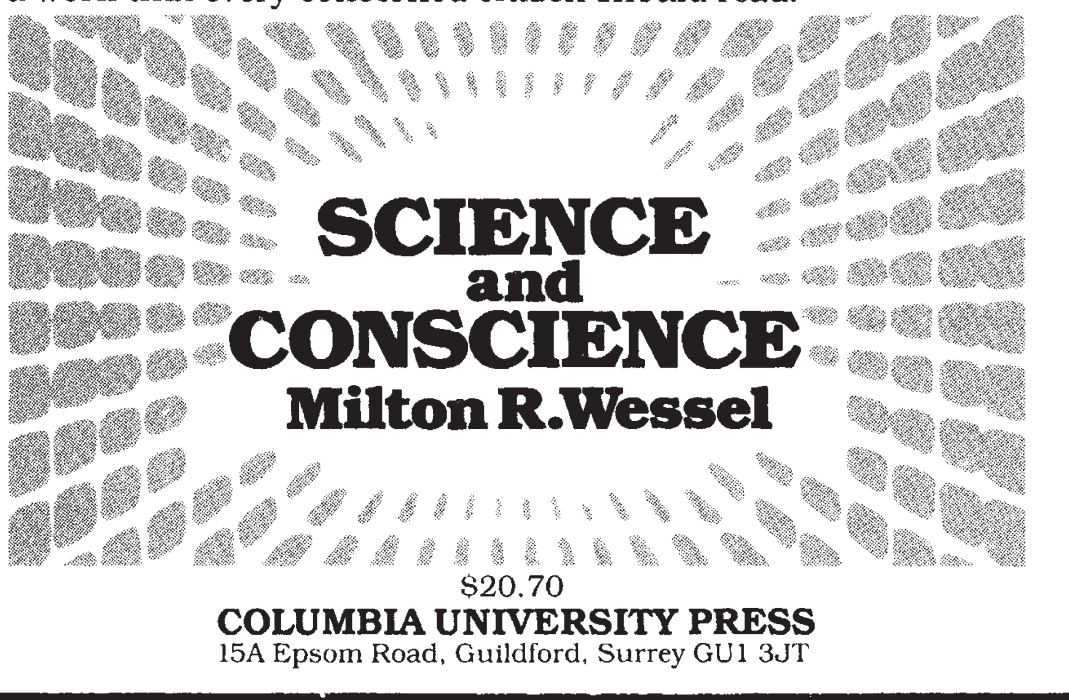

phagocytes from Edelson and from Egal and Davies.

It is impossible to do justice to all the book's 18 chapters in a brief review; the topics cover an astonishingly wide range, from "template activity of isolated lymphocyte nuclei in priming exogenous bacterial RNA polymerase", through "eosinopoiesis and mast cell desensitisation" to "the ultrastructure of prelymphatics and tissue channels that constitute the sol phase of interstitial tissue". However, although the coverage is eclectic, this book is not a collection of esoterica the balance is good and the tone is authoritative, inasmuch as it can be with a subject such as this where so much still remains to be learned.

There are, of course, some disappointments: for example, the reviews of the fastmoving areas of research are already dated, because most of the literature surveys seem to have stopped at the beginning of 1978 , and some even earlier. Also, there is inevitable overlap with some parts of Vol. 1 in this series (Chemical Messengers of the Inflammatory Process), but this is a much better book than its predecessor - so much so that one wonders what remains for future volumes in this series. The standard of production is high and the copy is clean - Graham Lewis's criticism of the proofreading of Vol. 1 (Nature 286, 89; 1980) perhaps had a salutary effect.

In summary, this is a substantial and important volume, and it deserves to be widely read; it left me with the impression that it could have been subtitled "all you wanted to know about inflammation but were afraid to look for in the original literature'. It provides a valuable source of information and reference for those already working on some aspect of the cell biology of inflammation, and it may also stimulate those working on other topics to enter this fascinating field. of Animal Physiology, Cambridge. 